\title{
Satisfied or exhaustified: An ambiguity account of the Proviso Problem*
}

\author{
Clemens Mayr \\ ZAS
}

\author{
Jacopo Romoli \\ Ulster University
}

\begin{abstract}
The presuppositions inherited from the consequent of a conditional or the second disjunct of a disjunction oscillate between a conditional and a nonconditional inference, depending on the context. This is problematic for most theories of presupposition projection in the literature, which only predict a conditional presupposition for such sentences (Karttunen 1974; Stalnaker 1973; Heim 1983; Beaver 2001; Schlenker 2009; Fox 2008 among others). The general response to this problem, the so-called 'Proviso Problem' (Geurts 1996), is to assume that in addition to the basic conditional presupposition, a non-conditional inference can arise depending on the relationship between the antecedent/first disjunct and the presupposition of the consequent/second disjunct. We discuss data for which this solution makes the wrong predictions. Similar data have been taken by van der Sandt (1992), Geurts (1996) and Garcia-Odon (2012) to motivate the DRT-approach to presuppositions. Schlenker (2011), however, has raised various arguments against such an approach. We propose an alternative analysis, which doesn't have those problems. In our analysis, the differing presuppositions are the result of a systematic ambiguity involving exhaustification in a trivalent semantics: a non-conditional presupposition obtains with exhaustification, and a conditional one without. Independently motivated plausibility considerations decide which reading is chosen with no direct selection of presuppositions needed. We discuss how this approach deals with the various cases of proviso and the predictions it makes for biconditional sentences.
\end{abstract}

Keywords: presuppositions, presupposition projection, exhaustification, Proviso Problem

\section{Introduction}

The presuppositions inherited from the consequent of a conditional or the second disjunct of a disjunction oscillate between a conditional and a non-conditional inference, depending on the context; a phenomenon generally known as the 'Proviso Problem' (Geurts 1996). ${ }^{1}$ To illustrate, consider the following examples in (1) and

* For helpful comments and suggestions, we would like to thank Emmanuel Chemla, Irene Heim, Matt Mandelkern, Paolo Santorio, Philippe Schlenker, Yasu Sudo and the audiences at ZAS and SALT 26. 1 The problem was already discussed in Karttunen \& Peters 1979 and Gazdar 1979 among others. 
(2), adapted from Pérez Carballo 2009.

(1) a. If John isn't tired, he'll read his Bible.

b. Either John is tired, or he'll read his Bible.

c. $\Varangle$ If John isn't tired, he has a Bible

d. $\rightsquigarrow$ John has a Bible

(2) a. If John is Catholic, he'll read his Bible.

b. Either John isn't Catholic, or he'll read his Bible.

c. $\rightsquigarrow$ If John is Catholic, he has a Bible

d. $\rightsquigarrow$ John has a Bible

The conditional and the disjunctive sentences in (1a) and (1b) intuitively suggest that John has a Bible as in (1d). ${ }^{2}$ They do not suggest that if he isn't tired then he has a Bible as in (1c). However, the two sentences in (2a) and (2b) could be taken to suggest the weaker conditional inference (2c) that John has a Bible if he is Catholic. ${ }^{3}$

Most theories of presuppositions in the literature predict that both (1) and (2) should project the conditional presupposition in (1c) and (2c), which is problematic at least for the case of (1) (Stalnaker 1973; Karttunen 1974; Heim 1983, 1990, 1992; Beaver 2001; Schlenker 2008, 2009; Fox 2008; George 2008; Rothschild 2011 among many others). However, a standard response to the Proviso Problem compatible with these accounts is to argue that under certain conditions, the sentences above can be associated with the stronger non-conditional presupposition in (1d) and (2d) (Karttunen \& Peters 1979; Beaver 2001; Heim 2006; Singh 2007, 2008; von Fintel 2008; Schlenker 2011; Stalnaker 2014; Pérez Carballo 2009; Lassiter 2012; see also Mandelkern 2016b). The 'certain conditions' under which the nonconditional presupposition arises differ across different accounts of Proviso; in all accounts, however, they are such that the non-conditional presupposition arises systematically in cases like (1) but only optionally - if ever - in cases like (2).

In the present paper, we argue that both the conditional and the non-conditional inference directly correspond to different presuppositions of the sentences above and whether a non-conditional presupposition obtains depends on whether the conditional receives a 'perfected' interpretation ${ }^{4}$ or the disjunction is interpreted exclusively.

2 In the following $\rightsquigarrow$ indicates an inference that a sentence is intuitively taken to have without a commitment as to the nature of this inference.

3 In the literature, cases like (2) are sometimes characterized as only having the weak conditional presupposition in (2c). Given the entailment relation from (2d) to (2c) which makes the latter always true where the former is, we assume that the stronger inference in (2d) is also possible in absence of evidence to the contrary (see Meyer \& Sauerland 2009 among others).

4 'Perfected' in the sense of Geis \& Zwicky 1971; see also von Fintel 2001 and references therein. 
In other words, we align the conditional versus non-conditional presupposition distinction with the strengthened versus non-strengthened meaning of the sentences so that the two kinds of presuppositions observed are the consequence of genuine truth-conditional ambiguity. In addition, we show that for sentences like those in (1), unlike those in (2), the reading involving a conditional presupposition would go against plausibility considerations and is therefore blocked for independent reasons.

The motivation for this account is both theoretical and empirical. First, we note that accounts of presupposition projection like the trivalent Strong Kleene approach (Peters 1979; Beaver \& Krahmer 2001; Fox 2008; George 2008; Chemla \& Schlenker 2012 among others) and accounts based on incremental transparency (Schlenker 2008, 2009) predict that biconditional sentences like (3a) should project a non-conditional inference, unlike what they predict for simple conditionals. We make the novel observation that this prediction is in fact borne out. For instance, the biconditional (3a) seems to suggest that John has a Bible more strongly than (2a) does.
a. John is Catholic if and only if he will read his Bible tonight.
b. $\rightsquigarrow$ John has a Bible

Second, we argue that this difference between biconditionals and simple conditionals is at the basis of a solution for problematic examples like those in (4) and (5) (adapted from van der Sandt 1992; Geurts 1996; Garcia-Odon 2012; Katzir \& Singh 2013). In (4a) and (5a) the antecedent strictly entails the presupposition of the consequent, and in (4b) and (5b) it is the negation of the first disjunct that strictly entails the presupposition of the second disjunct. The key point here is that (4a) and (4b) intuitively can be read as having an inference that John went to Europe and (5a) and (5b) that the speaker's best student left. ${ }^{5}$ Existing accounts of the Proviso Problem such as the ones mentioned above, however, predict the sentences to have tautological conditional presuppositions and thus to be presuppositionless.

(4) a. If John is in Berlin, he is happy that he went to Europe.

b. Either John isn't in Berlin or he's happy he went to Europe.

c. $\rightsquigarrow$ If John is in Berlin, John went to Europe

d. $\rightsquigarrow$ John went to Europe

(5) a. If all students left, the janitor didn't realize that my best student left.

b. Either not all students left or the janitor didn't realize that my best student left.

5 These types of examples go back to Soames 1979 and have been used as arguments against Gazdar's (1979) theory, because they have a reading associated with a weak, in fact tautological, conditional presupposition which the latter account does not predict (see the discussion in Heim 1990). 


$$
\begin{aligned}
& \text { c. } \rightsquigarrow \text { If all students left, my best student left } \\
& \text { d. } \rightsquigarrow \text { My best student left }
\end{aligned}
$$

In our analysis, the presence or absence of the inference in question is the result of a systematic ambiguity between strengthening (perfection of the conditional or exclusivity of the disjunction) and non-strengthening: a non-conditional inference obtains with strengthening, and a conditional, tautological one without. Independently motivated plausibility considerations decide which reading is chosen with no direct selection of presuppositions needed.

The rest of the paper is structured as follows: Section 2 discusses the Proviso Problem in more detail and points out complications for existing accounts. Section3 introduces the new account. This account is couched in a Strong Kleene approach to presupposition projection and covers the problematic cases mentioned. In Section4 the account is extended to further data connected to the Proviso Problem. Section5 concludes the paper.

\section{The Proviso Problem}

\subsection{The Proviso Problem}

Recall once more the examples from (1) and (2), repeated as (6) and (7) respectively. Both sentences in (6) suggest that John has a Bible, while both sentences in (7) can be taken to suggest that if John is Catholic he has a Bible.

(6) a. If John isn't tired, he'll read his Bible.

b. Either John is tired, or he'll read his Bible.

c. $\psi$ If John isn't tired, he has a Bible

d. $\rightsquigarrow$ John has a Bible
a. If John is Catholic, he'll read his Bible.
b. Either John isn't Catholic, or he'll read his Bible.
c. $\rightsquigarrow$ If John is Catholic, he has a Bible
d. $\rightsquigarrow$ John has a Bible

Gazdar (1979) and Geurts (1996) take the fact that the sentences in (6) appear to only be associated with the non-conditional presupposition in (6d) as problematic for those theories of presupposition projection that instead predict the conditional presupposition in (6c) for such sentences. ${ }^{6}$ The criticism is that an empirically

6 In Gazdar's case the criticism was originally leveled at Karttunen \& Peters's (1979) multi-dimensional description of presupposition projection patterns based in turn on Karttunen's (1973) observations. 
adequate theory of presupposition projection should predict a non-conditional presupposition for such examples. In response to this problem, one could hold that the predicted conditional presupposition seems to be just fine once examples like those in (7) are considered. The argument would go as follows: the predicted conditional presupposition is adequate for both (6) and (7). It just so happens that a stronger inference is sometimes associated with such cases (see Karttunen \& Peters 1979; Beaver 2001; Heim 2006; Singh 2007; van Rooij 2007; Singh 2008; von Fintel 2008; Schlenker 2011; Stalnaker 2014; Pérez Carballo 2009; Lassiter 2012 among others). One implementation of this approach is based on accommodation (Heim 2006; von Fintel 2008; Beaver 2001 among others). If a sentence like the above is uttered in a context which does not entail the conditional presupposition, the hearer could choose to accommodate such a conditional presupposition or the stronger non-conditional one (we will come back below to the conditions regulating this choice). If the non-conditional presupposition is the one which gets accommodated, the weaker conditional presupposition cannot be accessed by intuitions anymore.

\subsection{The choice between conditional and non-conditional presuppositions}

We will now discuss what seems to us to be a core feature of replies, such as the one just sketched, to Gazdar's (1979) and Geurts's (1996) criticism.

As discussed, accounts of the Proviso Problem have to provide a solution to what Schlenker (2011) calls the 'selection problem.' That is they have to spell out the conditions under which a conditional sentence like the above is associated with a non-conditional presupposition as opposed to a conditional one. While the details vary across different accounts, they agree on the idea that the selection mechanism is constrained by a notion of independence: if the antecedent (or the negation of the first disjunct) is independent in some sense from the presupposition of the consequent (or the second disjunct) the non-conditional presupposition will arise (von Fintel 2008; van Rooij 2007; Singh 2008; Schlenker 2011; Pérez Carballo 2009; Lassiter 2012; see also Mandelkern 2016b).

To get an intuitive grasp of how this predicts the right presupposition for sentences like (6) and (7) above, let us discuss Lassiter's (2012) account in a bit more detail. Roughly, in this account, the non-conditional presupposition arises depending on whether the truth of the presupposition of the consequent (or second disjunct) is likely to be dependent on the truth of the antecedent (or negation of the first disjunct) or whether it is more plausible to be independent of it. For instance, a hearer faced with either the conditional or the disjunctive sentence in (6) will conclude that John's state of tiredness is independent of him having a Bible and will therefore go for the non-conditional presupposition that John has a Bible. In the case of (7), however, it is not implausible that John's having a Bible is dependent on him being 
Catholic. For that reason, the conditional presupposition that John has a Bible, if he is Catholic will arise. But in principle nothing prohibits the stronger non-conditional presupposition to arise even in this case. That is, the examples in (7) can have both types of presuppositions depending on the particular context.

\subsection{Problematic data for existing accounts}

In addition to the classical proviso data above, there are examples like those in (4) and (5) above. As mentioned, the crucial feature of these examples is that the antecedent or negation of the first disjunct strictly entails the presupposition of the consequent or second disjunct. As also said, the examples appear to have a reading with a clear unconditional inference that John went to Europe and that the speaker's best student left, respectively. Examples of that sort are not generally discussed when dealing with the Proviso Problem (with the exception of van Rooij 2007 and Katzir \& Singh 2013). They, however, can be seen as parallel to examples like (7): the absence of an inference is simply the result of a tautological, conditional presupposition, which is the one predicted for the cases considered. The non-conditional inference, on the other hand, corresponds to the stronger non-conditional presupposition. In other words, there would be two candidate presuppositions: a tautological one and a non-tautological one. The component of an account of the Proviso Problem dealing with the 'selection problem' mentioned in the preceding section should therefore select one of them depending on what is the more plausible inference. ${ }^{7}$

The problem is that all of the accounts mentioned only predict the conditional presupposition. That is, they predict all the sentences in (4) and (5) to be presuppositionless. For instance, in Lassiter's account the presupposition of the consequent or second disjunct is necessarily dependent on the antecedent or negation of the first disjunct. The reason for that is that the latter entails the former (e.g., all students left entails that my best student left). That is, learning the truth of the antecedent (or the negation of the first disjunct) changes the degree of belief in the presupposition of the consequent (or second disjunct) given this entailment relation. Therefore, the non-conditional presupposition is predicted to be unavailable, against intuitions.

A first response to this problem could be to argue that the non-conditional inference in this case is not a presupposition of the sentence. However, tests targeting the presuppositional status of an inference suggest that the non-conditional inference

7 It must be noted that accounts of the Proviso Problem relying on the assumption that accommodation is only forced when the context does not entail the predicted sentence presupposition such as Heim's (2006) and Singh's (2007) proposals do not allow for a stronger presupposition in (4) and (5). The reason is that the sentence presupposition is tautological. Any context entails this presupposition. Thus there is no need for accommodation and the stronger non-tautological presupposition cannot surface. Of course, it then remains a mystery why the examples can be read with the stronger inference at all. See the text for more discussion of this. 
in question is indeed presuppositional. For instance, the Hey wait a minute-test (von Fintel 2008) shows that one can target the non-conditional inference by pointing out that it is not part of the common ground. While this test is not a perfect test for presuppositionality, it is definitely suggesting that the non-conditional inference here is a presupposition.

a. A: If John is in Berlin, he is happy that he went to Europe.

b. B: Hey, wait a minute. I didn't know John went to Europe!

Moreover, the non-conditional inference projects out of questions as in (9a) and antecedents of conditionals as in (9b). Again, this property is essential for an inference to be classified as a presupposition.

(9) a. If John is in Berlin, is he happy that he went to Europe?

b. If John is in Berlin and he is happy that he went to Europe, he will be in touch shortly.

c. $\rightsquigarrow$ (If John is in Berlin, ) John went to Europe

Another response to the problem, suggested by van Rooij (2007) and Katzir \& Singh (2013), is to argue that examples like (4) and (5) would trigger the accommodation of a question under discussion which itself carries a non-tautologous inference. For instance, A's question in (10a) presupposes that John went to Europe. Therefore $\mathrm{B}$ will himself be taken to share that presupposition. In that case, however, one cannot determine whether B's utterance has a tautologous or non-tautologous presupposition. Thus we cannot conclude anything about the presupposition of (10b).

(10) a. A: Is John happy that he went to Europe?

b. B: If he is in Berlin, he is happy that he went to Europe.

We think, however, that this cannot be the whole story. Consider the conversation in (11): B's utterance is acceptable after a question that does not presuppose that John is in Europe. Moreover, given the existence of an overt question, accommodation of a further question under discussion with the called for presupposition is unlikely in that situation. And crucially B's utterance in (11) can still be taken to suggest that John is in Europe.

(11) a. A: Tell me something about John. What is he doing this summer?

b. B: If he is in Berlin, he is happy that he went to Europe.

Summarizing, it seems that the non-conditional inferences of the examples in (4) and (5) should be classified as presuppositions. And none of the approaches reviewed above can account for this fact. Now, it must be noted that van der Sandt (1992), 
Geurts (1996) and Garcia-Odon (2012) offer DRT-accounts of examples similar to the relevant ones above-that is, the facts just discussed are taken by them as evidence that presupposition projection should be dealt with in a DRT-based framework. Schlenker (2011), however, has raised various serious problems for such an approach. For this reason, we explore an alternative solution to which we turn now.

\section{The account}

\subsection{Presuppositions and presupposition projection in trivalent semantics}

\subsubsection{Presuppositions in trivalent semantics}

A trivalent system is based on three truth-values: 1,0 , and the third value \#. A non-complex sentence $\phi_{p}$ with $p$ the presupposition of $\phi$ has the third value \# in a world $w$ whenever $p$ is 0 in $w$. For instance, assuming that the factive predicate in (12) introduces the presupposition that John is in Europe, it should follow that (12) is \# in every world in which John is not in Europe.

(12) John regrets that he is in Europe.

Given this, we can define a notion of presupposition as follows in a trivalent system (Beaver \& Krahmer 2001), which has the desired consequence for (12):

\section{(13) Presupposition in trivalent semantics}

A sentence $\phi$ presupposes $p$ iff $\forall w: p(w)=0 \rightarrow \llbracket \phi \rrbracket(w)=\#$.

From this definition of presupposition alone it does not follow that (12) is only acceptable in contexts in which at least the speaker of the sentence takes John to be in Europe. It turns out, however, that this can be guaranteed given a natural pragmatic principle (see Beaver \& Krahmer 2001; von Fintel 2008; Fox 2008). According to Stalnaker (1979) a speaker asserting a sentence is taken to assume that the sentence does not receive the third value in any world in the context. This is known as the bridge principle - the bridge between compositional semantics and the pragmatics of assertion:

\section{(14) Stalnaker's bridge principle}

A sentence $\phi_{p}$ is assertable in context $c$ iff $\forall w \in c: \llbracket \phi \rrbracket(w) \neq \#$.

In other words, the presupposition of a sentence $\phi_{p}$ can be seen as what it takes for the sentence not to receive the third value. Given (14) it follows for (12) that its speaker must assume that John is in Europe. For otherwise, he could not assert (12). 


\subsubsection{Presupposition projection in Strong Kleene semantics}

How does one determine the presuppositions of a complex sentence $\phi$ with subsentence $\psi_{p}$ ? That is, how does the presupposition $p$ of $\psi$ project? As noted by Peters (1979), Beaver \& Krahmer (2001), Fox (2008), and George (2008) Strong Kleene semantics gives largely adequate results. In such a system $\phi$ does not automatically receive the third value \# just because $\psi_{p}$ does so. Rather, $\phi$ only receives \# if a standard bivalent system could not determine a bivalent truth-value regardless of $\psi_{p}$ 's third value. ${ }^{8}$ Consider the Strong Kleene truth-tables for the conditional and the disjunction in (15).

\begin{tabular}{c|ccc}
$\rightarrow$ & 1 & 0 & $\#$ \\
\hline 1 & 1 & 0 & $\#$ \\
0 & 1 & 1 & 1 \\
$\#$ & 1 & $\#$ & $\#$
\end{tabular}

\begin{tabular}{c|ccc}
$\vee$ & 1 & 0 & $\#$ \\
\hline 1 & 1 & 1 & 1 \\
0 & 1 & 0 & $\#$ \\
$\#$ & 1 & $\#$ & $\#$
\end{tabular}

For a statement if $\phi, \psi_{p}$ it follows given the truth-table for the conditional connective that the third-value of $\psi_{p}$ only matters in case $\phi$ does not receive 0 . The reason for this is simple: in a bivalent semantics a conditional receives the value 1 as soon as the antecedent is 0 . As a consequence a Strong Kleene system assigns in this case the value 1 to if $\phi, \psi_{p}$ even if $\psi_{p}$ is \#. If $\phi$ is 1 , on the other hand, a bivalent system cannot assign a value to the whole conditional. In case $\psi_{p}$ is 1 the whole is 1 , and in case it is 0 the whole is 0 . Given the definition of presupposition in (13) it follows that if $\phi, \psi_{p}$ does not presuppose $p$ because there are worlds where $p$ is 0 and if $\phi, \psi_{p}$ is not \#. However, because of what has just been said if $\phi$, $\psi_{p}$ presupposes $\phi \rightarrow p$ : whenever this proposition is 0 , if $\phi, \psi_{p}$ is \#. Given the bridge principle in (14) it follows that if $\phi, \psi_{p}$ is only assertable in a context such that if $\phi$ is $1, p$ is 1 too. So the speaker of if $\phi, \psi_{p}$ presupposes that for all $w \in c$, $\phi(w)=1 \rightarrow p(w)=1$. It follows that both (16) and (17), repeated from above, receive conditional presuppositions. As we know, this is desirable for the latter but not necessarily for the former. Thus the Proviso Problem carries over to an account of presupposition projection based on Strong Kleene semantics.

8 The results are adequate insofar as one restricts one's attention to presuppositions contained in the final subsentence linearly speaking. Here the standard Strong Kleene truth-tables make the correct predictions regarding filtering of presuppositions. As noticed by Peters (1979) based on Karttunen's (1973) observations, however, presuppositions in non-final subsentences should not be filtered. That is, the symmetry imposed by the Strong Kleene truth-tables should be broken. Peters therefore proposes asymmetric Strong Kleene truth-tables. Fox (2008), building on Schlenker 2008, shows that this is not necessary. One can use the standard Strong Kleene truth-tables provided one incrementalizes the system by adopting Schlenker's (2008) transparency-based system of pragmatic parsing. In order to avoid this complication, our examples have the presupposition trigger always in the final subsentence. 
(16) If John isn't tired, he'll read his Bible.

(17) If John is Catholic, he'll read his Bible.

For completely parallel reasons the truth-table for disjunction in (15) together with the bridge principle determines for a sentence $\neg \phi$ or $\psi_{p}$ that the speaker presupposes that if $\neg \phi$ is $0, p$ is 1 . The reason for this is that only in case the first disjunct is 0 the truth-value of the second disjunct matters for determining the truth-value of the whole disjunction under a bivalent semantics. Thus both (18) and (19) receive a conditional presupposition. Again, this is only clearly desirable in the latter case.

(18) Either John is tired, or he'll read his Bible.

(19) Either John isn't Catholic, or he'll read his Bible.

\subsection{A novel observation about strengthening in Strong Kleene semantics}

At this point it must be noted that the projection patterns in such a set-up are determined completely by the truth-tables for the connectives. Now, the Strong Kleene truth-tables for the biconditional and the exclusive disjunction look as follows:

\begin{tabular}{c|ccc}
$\leftrightarrow$ & 1 & 0 & $\#$ \\
\hline 1 & 1 & 0 & $\#$ \\
0 & 0 & 1 & $\#$ \\
$\#$ & $\#$ & $\#$ & $\#$
\end{tabular}

\begin{tabular}{c|ccc}
$\nabla$ & 1 & 0 & $\#$ \\
\hline 1 & 0 & 1 & $\#$ \\
0 & 1 & 0 & $\#$ \\
$\#$ & $\#$ & $\#$ & $\#$
\end{tabular}

This has consequences for presupposition projection. Consider a sentence of the form if $f_{\text {perf }} \phi, \psi_{p}$. In general in a bivalent system, a biconditional is 1 if and only if the antecedent and the consequent have the same truth-value and 0 otherwise. Therefore if $\psi_{p}$ is \#, a bivalent semantics can neither decide on a bivalent truth-value for if perf $\phi, \psi_{p}$ when $\phi$ is 1 nor when it is 0 . In other words, in contrast to the unidirectional conditional discussed in the preceding section, the truth-value of $\psi_{p}$ matters both in case $\phi$ is 1 and in case it is 0 . Since this means that there are no worlds in which $p$ is 0 and if perf $\phi, \psi_{p}$ receives a bivalent value, it follows that if perf $\phi, \psi_{p}$ presupposes $p$ under the definition given above.

From this it follows that (16) and (17) read with a perfected interpretation of the conditional presuppose that John has a Bible. As we know this is the desired result for the former but not for the latter example. For (17) we do, however, have a way of deriving the desired conditional presupposition-namely via a unidirectional interpretation of the conditional as pointed out above.

A direct prediction of this is that an overtly biconditional version of (17) should necessarily project the presupposition that John has a Bible. As mentioned when discussing (3a), repeated in (21a), this prediction is borne out. 
(21) a. John is Catholic if and only if he will read his Bible.

b. $\rightsquigarrow$ John has a Bible

In parallel to the biconditional case, $\neg \phi o r_{\text {excl }} \psi_{p}$ presupposes $p$ given the truth-table for exclusive disjunction in (20). In a bivalent system, an exclusive disjunction is 1 if and only if one disjunct is 1 and the other 0 , and 0 otherwise. Because of this a bivalent system cannot decide on a value for $\neg \phi$ or $\psi_{p}$ if $\psi_{p}$ is \#. It thus follows that (18) and (19) presuppose that John has a Bible if the disjunction is read exclusively. Again, this is not clearly desirable in the latter case, but the inclusive interpretation allows us to also predict a conditional presupposition.

In parallel to the prediction about (21a), it follows that an unquestionably exclusive variant of (19) should presuppose that John has a Bible. It is more difficult to determine whether this prediction is borne out. But (22a) seems to go in the right direction, at least when compared to (19).

(22) a. Either John isn't Catholic, or he'll read his Bible, but not both.

\section{b. ?œ John has a Bible}

It should be pointed out that the predictions discussed also hold for theories of presupposition projection based on the notion of transparency (Schlenker 2008, 2009). This is shown by Mayr \& Romoli (2016), who also show that the predictions are welcome not only for presupposition projection but also for a puzzle for theories of redundancy in certain disjunctive sentences.

\subsection{Accounting for the proviso cases}

We have seen that a conditional and disjunctive sentence with a presupposition in the final subsentence can be read as either projecting a conditional presupposition or a non-conditional presupposition. Which presupposition is projected depends on whether the connective is interpreted as strengthened or not. This truth-conditional ambiguity between strengthened and non-strengthened interpretation, we claim, is at the basis of the account of the Proviso Problem.

But why do the examples in (23) seemingly only have the unconditional presupposition, which in our case means that the connectives must be interpreted as strengthened? And why can the sentences in (24) have both presuppositions, which for us means that the sentences are genuinely truth-conditionally ambiguous?
a. If John isn't tired, he'll read his Bible.
b. Either John is tired, or he'll read his Bible.
c. $\not$ If John isn't tired, he has a Bible
d. $\rightsquigarrow$ John has a Bible 
(24) a. If John is Catholic, he'll read his Bible.

b. Either John isn't Catholic, or he'll read his Bible.

c. $\rightsquigarrow$ If John is Catholic, he has a Bible

d. $\rightsquigarrow$ John has a Bible

We submit that the reason for the pattern in (23) and (24) is due to the fact that not all theoretically possible interpretations are equally plausible. Consider first the sentences in (23). When given a non-strengthened interpretation, we get a result paraphrasable as in (25), but when read strengthened (26) follows. Here and in the following the predicted presuppositions are underlined. The former presupposes that John has a Bible if he isn't tired and states that he will read it. This is generally less plausible given real-world knowledge than the latter interpretation, which simply presupposes that John has a Bible and states that he will read it if and only if he isn't tired. This is the reason why (26) is the accessible interpretation of (23).

NON-STRENGTHENED (23): If John isn't tired, he has a Bible and he'll read it if he isn't tired.

(26) STREngthened (23): John has a Bible and he'll read his Bible if and only if he isn't tired.

For (24) the possible interpretations are as in (27) and (28). Here it turns out that the conditional and the non-conditional presupposition are equally plausible given real-world knowledge if no further information is provided. Thus both interpretations should be available.

(27) NON-STREngthened (24): If John is Catholic, he has a Bible and if he is Catholic, he'll read it.

(28) STRENGTHENED (24): John has a Bible and John will read his Bible if and only if he is Catholic.

Thus the present account predicts the intuitive presuppositions available for conditionals and disjunctions with presupposition triggers in the final subsentence correctly. Notice that in contrast to other accounts of the Proviso Problem, the plausibility measure just sketched is a general one not tied to the specific account. In particular, the plausibility measure is the same that is at work at cases of genuine ambiguity such as quantifier scope readings. It works over meanings as a whole and not just presuppositions.

Finally, let us return to the examples in (29) and (30) once more. We showed that standard accounts of the Proviso Problem predict them to have a tautologous conditional presupposition, i.e., to be presuppositionless. 
Satisfied or exhaustified

(29) a. If John is in Berlin, he is happy that he went to Europe.

b. Either John isn't in Berlin or he's happy he went to Europe.

c. $\rightsquigarrow$ If John is in Berlin, John went to Europe

d. $\rightsquigarrow$ John went to Europe

(30) a. If all students left, the janitor didn't realize that my best student left.

b. Either not all students left or the janitor didn't realize that my best student left.

c. $\rightsquigarrow$ If all students left, my best student left

d. $\rightsquigarrow$ My best student left

The present account, however, straightforwardly generates the intuitively available non-conditional inferences for (29) and (30) as a presupposition. Consider, for instance, the latter example. Similarly to (24) above both the strengthened and the non-strengthened interpretations are plausible. Note in particular that since we do not compare the presuppositions directly but rather the meanings as a whole, it does not follow for us that the tautologous presupposition is chosen.

NON-STRENGTHENED (30): If all students left, my best student left and if all students left, the janitor didn't realize that my best student left.

(32) STRENGTHENED (30): My best student left and the janitor didn't realize that my best student left if and only if all students left.

\subsection{The account in more detail}

How do the strengthened interpretations of conditionals and disjunctions come about? For concreteness, following a wide-spread approach to the exclusive interpretation of disjunction, we assume that this is done via the process of exhaustification. In particular, we assume an exhaustivity operator which when applied to a prejacent asserts it and negates its excludable alternatives (see Fox 2007; Chierchia, Fox \& Spector 2012 among many others). It is defined as in (33a). The set of excludable alternatives is defined in $(33 \mathrm{~b}):^{9}$

$$
\begin{aligned}
& \text { a. } \operatorname{exh}(\mathscr{A} l t(p))(p)(w)=p(w) \wedge \forall q \in \mathscr{E} x c l(p, \mathscr{A} l t(p))[\neg q(w)] \\
& \text { b. } \mathscr{E} x c l(p, \mathscr{A} l t(p))= \\
& \quad\{q \in \mathscr{A} l t(p): p \nsubseteq q \wedge \neg \exists r[r \in \mathscr{A} l t(p) \wedge(p \wedge \neg q) \subseteq r]\}
\end{aligned}
$$

9 The definition of excludable alternatives is a simplified one, which suffices for our present concerns. For the more accurate definition see Fox 2007. 
Following among others Sauerland (2004) a disjunction of the form not- $\phi$ or $\psi$ is assumed to have the standard alternatives in (34). The exhaustivity operator will thus negate the conjunctive alternative yielding an exclusive interpretation as in (35). The remaining alternatives are not negated; for each it holds that the conjunction of its negation with the prejacent entails the respective other alternative, which according to (33b) blocks it from being in the set of excludable alternatives. From the exclusive interpretation it follows under a Strong Kleene approach that presuppositions project unfiltered from both disjuncts and in particular from the second disjunct, as discussed above. This can be seen from (36).

$$
\begin{aligned}
& \mathscr{A} l t(\neg A \vee B)=\mathscr{A} l t(A \rightarrow B)=\{\neg A \vee B, \neg A, B, \neg A \wedge B\} \\
& \operatorname{exh}(\neg A \vee B)=(\neg A \vee B) \wedge \neg(\neg A \wedge B) \\
& \operatorname{exh}\left(A \vee B_{p)}=\operatorname{exh}\left(\neg A \rightarrow B_{p}\right)=\left(A \vee B_{p}\right) \wedge \neg\left(A \wedge B_{p}\right) \rightsquigarrow p\right.
\end{aligned}
$$

For simplicity, we assume that the conditional is interpreted as material implication and that it is associated with the same alternatives as disjunction, as stated in (34). From this it immediately follows that we make the same predictions as for disjunction with regards to strengthening as given in (37). Moreover, we make therefore the same predictions with regards to projection as can be seen from (38).

$$
\begin{aligned}
& \operatorname{exh}(A \rightarrow B)=(A \rightarrow B) \wedge \neg(\neg A \wedge B)=(A \rightarrow B) \wedge(B \rightarrow A) \\
& \operatorname{exh}\left(A \rightarrow B_{p}\right)=\left(A \rightarrow B_{p}\right) \wedge \neg\left(\neg A \wedge B_{p}\right)=\left(A \rightarrow B_{p}\right) \wedge\left(B_{p} \rightarrow A\right) \rightsquigarrow p
\end{aligned}
$$

Notice however that we need not necessarily make the assumption that disjunction and conditional share their alternatives. For us any way of getting to the conditional perfection interpretation will give rise to the desired projection property discussed above. For instance, we could assume any account of conditional perfection among Ducrot 1969; Matsumoto 1995; van der Auwera 1997; von Fintel 2001; Franke 2011; Herburger 2015 among others.

\section{Other cases}

In this section, we show that our account successfully extends to other aspects of the Proviso Problem. We close with an open issue about cases in which the non-conditional inference appears to arise obligatorily.

\subsection{Factives}

In addition to the original cases of proviso, Geurts (1996) also made the challenge from the Proviso Problem more severe by pointing out that the conditional presupposition is never strengthened when it arises from other presuppositional environments, regardless of considerations of plausibility. In particular, he shows that factive 
Satisfied or exhaustified

sentences like (39a), the complement of which corresponds to the conditional presupposition of the cases above, can only have the conditional presupposition in (39b). That is, despite being implausible, (39b) can never be strengthened to the non-conditional presupposition in (39c).

(39) a. Sue knows that if John isn't tired, he has a Bible.

b. $\rightsquigarrow$ If John isn't tired, he has a Bible

c. $\not \rightarrow$ John has a Bible

Sentences like (39a) are indeed a serious problem for the accounts discussed in section 2.2. From their perspective, one would have to ask why accommodation of (39c) is never possible when one faces (39a). On the present account this issue does not arise. It is easy to show that neither global, (40a), nor local exhaustification, (40b), can give rise to anything other than the conditional inference in (39b).

a. exh[Sue knows that if John isn't tired, he has a Bible]

b. Sue knows that exh[if John isn't tired, he has a Bible]

More precisely, in (40a) exhaustification is vacuous and therefore the conditional presupposition remains untouched. In (40b), the complement is locally strengthened to a biconditional, so the presupposition of (39a) becomes a biconditional inference: John isn't tired if and only if he has a Bible. Crucially, however, the latter is not the non-conditional inference that John has a Bible.

In sum, our proposal can straightforwardly account for the problem with factive sentences like (39a) raised by Geurts (1996). In the next subsection, we turn to cases of proviso involving quantifiers and we show that our approach has no problem accounting for those either.

\subsection{Quantifiers}

Schlenker (2011) discusses cases of the Proviso Problem involving quantifiers like (41a), giving rise to the non-conditional inference in (41b). ${ }^{10}$

(41) a. If I don't give an exam, none of my students will realize that he is incompentent.

b. $\rightsquigarrow$ Each of my students is incompetent

10 Schlenker (2011) shows that these data are problematic for DRT accounts. Essentially, the problem for DRT-based accounts is that the presupposition is necessarily accommodated in the scope of the quantifier. As a consequence, no inference such as (41b) can be projected contrary to intuition. 
Our approach can predict the presuppositional inference in (41b) if (41a) is exhaustified as in (42). Showing this would necessitate discussion of presupposition projection from quantifier scopes, which we cannot include here for reasons of space. Regardless of which presupposition is projected from the scope of the negative quantifier in (42), however, it should be clear that the perfected interpretation of the conditional will directly project that presupposition to the root.

(42) exh[If I don't give an exam, none of my students will realize that he is incompentent]

\subsection{Semi-conditional inferences}

Another challenging aspect of the Proviso Problem comes from sentences like (43a), embedding a conjunction in its antecedent. The problem is that (43a) tends to have a 'semi-conditional inference' as in (43b) - that is, an inference the antecedent of which corresponds to only one of the two conjuncts in the antecedent of the asserted conditional. This is problematic for many of the accounts of the Proviso Problem reviewed in section 2.2 .

(43) a. If John is 64 and is aware of our hiring policies, he knows we cannot hire him.

b. $\rightsquigarrow$ If John is 64 , we cannot hire him

While semi-conditional inferences are challenging for our proposal as well, we can derive them through contextual pruning of alternatives in the sense of Katzir (2007). To illustrate, consider that among the alternatives for (43a) we have the following two alternatives, obtained by simplifying the antecedent of the assertion to one of its conjuncts.

(44) If John is 64, he knows we cannot hire him.

(45) If John is aware of our hiring policies, he knows we cannot hire him.

Now, if we allow the context to restrict the set of alternatives in such a way as to include (44) but not (45), we end up with the following strengthened meaning for (43a):

(46) If John is 64 and is aware of our hiring policies, he knows we cannot hire him and it's not true that if John is 64 , he knows we cannot hire him.

It is easy to show that this reading of the sentence projects the presupposition in (47), which is equivalent to the desired semi-conditional presupposition that if John is 64 , we cannot hire him. 
Satisfied or exhaustified

(47) If John is 64 and he is aware of our hiring policies, we cannot hire him and if John is 64, we cannot hire him.

The prediction of this solution is that we link the particular reading in (46) with the projection of the semi-conditional presupposition. We find the reading in (46) indeed a natural reading of (43a). The judgment about whether the semi-conditional inference is necessarily associated with this reading, however, is a delicate one and we have to leave a more detailed investigation of this prediction to future work.

\subsection{Obligatory non-conditional inferences}

Mandelkern (2016b) has recently raised an important challenge to existing accounts of the Proviso Problem and theories predicting conditional presuppositions more in general (see also Mandelkern 2016a). In particular, he has argued that examples like (48a) are infelicitous because of the non-conditional inference they would give rise to-in this case the inference in (48c) that John has diabetes-which would clash with the speaker asserted ignorance in the preceding context. The puzzling aspect of examples like (48a) for accounts of Proviso is the apparent obligatoriness with which this non-conditional inference would be derived, in spite of the infelicity of the example. In other words, the question is why one cannot pragmatically select the conditional inference in (48b), which would be consistent with the context of (48a).

a. I don't know if John has diabetes or arthrites, but ... \#if he lowers his sugar intake at dinner tonight, his diabetes is under control.

b. If John lowers his sugar intake, he has diabetes

\section{c. John has diabetes}

This is a problem for all accounts that we know of. The challenge for our account takes the form of why non-exhaustification of (48a) is apparently impossible. If the infelicity of (48a) has as its source the non-conditional inference in (48c), we should be able to avoid this by not exhaustifying (48a). Why is this not an option?

While exploring a full solution for this problem is beyond the scope of this paper, we want to sketch an alternative direction to account for Mandelkern's (2016b) data. Here the alternative source of the oddness of (48a) would be that the latter is an attempt to answer the salient Question Under Discussion-Does John have diabetes or arthritis? - via a presupposition and this would independently be an infelicitous discourse move. Crucially, this assumption predicts infelicity for (48a) regardless of whether it is read with a conditional or a non-conditional inference. In either case, we would be trying to answer the QUD with a presupposition. ${ }^{11}$ This explanation

11 Mandelkern (2016b) considers an account relying on the QUD in his fn. 20 when asking why the 
would not need to assume that the non-conditional inference is generated obligatorily from (48a) at all. ${ }^{12}$

In sum, the data from Mandelkern (2016b) are challenging for accounts of the Proviso Problem, including ours. The alternative explanation sketched above, if ultimately viable, would allow us to maintain the general architecture of such accounts, while explaining the infelicity of the examples above independently. We leave a more detailed exploration of this for future work.

\section{Conclusion}

In this paper, we have put forward a proposal based on the observation that in certain theories of presupposition projection exhaustification influences projection. As we discussed, this provides a solution to data introduced by van der Sandt (1992) and Geurts (1996), which are problematic for most theories of presuppositions in the literature. In addition, the proposal can be extended to be a general solution to the Proviso Problem. We have also discussed how the proposal can account for various other instances of the problem, involving factives, quantifiers, and conditionals with conjunctions in their antecedents.

\section{References}

van der Auwera, Johan. 1997. Conditional perfection. In A. Athanasiadou \& R. Dirven (eds.), On Conditionals Again, 169-190. John Benjamins.

Beaver, David \& Emiel Krahmer. 2001. A partial account of presupposition projection. Journal of Logic, Language and Information 10(2). 147-182.

non-conditional presupposition is preferred over the conditional one and dismisses it. We agree with his reasons for doing so. The suggestion in the text is, however, not affected by his criticism as it is independent of why one presupposition is preferred over the other.

12 To be a serious alternative, this explanation should be developed in the following direction. Mandelkern (2016b) also notices that (ib) in a context in which the speaker does not assert ignorance with respect to the non-conditional inference intuitively gives rise to the inference that John has diabetes (and can be followed felicitously by responses like 'Hey wait a minute! I didn't know he had diabetes', (von Fintel 2004), as a further indication that the inference is there). Given the explanation above, this would have to be an independent fact about examples like (ib) which would favour a reading with the non-conditional inference. In our account, one would have to say that cases like (ib) strongly favour a conditional perfection reading, which in turn gives rise to the non-conditional presupposition.

(i) a. Is John in good health? Is he taking care of himself?

b. I'm not sure, but we should be able to tell at dinner:

if he's restricting his sugar intake, then his diabetes is under control. 
Satisfied or exhaustified

Beaver, David I. 2001. Presupposition and Assertion in Dynamic Semantics. Stanford University: CSLI Publications.

Chemla, Emmanuel \& Philippe Schlenker. 2012. Incremental vs symmetric accounts of presupposition projection: An experimental approach. Natural Language Semantics 20(2). 177-226.

Chierchia, Gennaro, Danny Fox \& Benjamin Spector. 2012. The grammatical view of scalar implicatures and the relationship between semantics and pragmatics. In Paul Portner, Claudia Maienborn \& Klaus von Heusinger (eds.), Semantics: An International Handbook of Natural Language Meaning 3, 2297-2331. Berlin: Mouton de Gruyter.

Ducrot, Oswald. 1969. Présupposés et sous-entendus. Langue Français 4. 30-43.

von Fintel, Kai. 2001. Conditional strengthening: A case study in implicature. Unpublished manuscript.

von Fintel, Kai. 2004. Would you believe it? The king of france is back! Presuppositions and truth-value intuitions. In Marga Reimer \& Anne Bezuidenhout (eds.), Descriptions and beyond, Oxford University Press.

von Fintel, Kai. 2008. What is accommodation, again? Philosophical Perspectives, 22, Philosophy of Language .

Fox, Danny. 2007. Free choice and the theory of scalar implicatures. In Uli Sauerland \& Penka Stateva (eds.), Presupposition and Implicature in Compositional Semantics, 71-120. Basingstoke: Palgrave.

Fox, Danny. 2008. Two short notes on Schlenker's theory of presupposition projection. Theoretical Linguistics 34(3). 237-252.

Franke, Michael. 2011. Quantity implicatures, exhaustive interpretation, and rational conversation. Semantics and Pragmatics 4(1). 1-82. doi:10.3765/sp.4.1.

Garcia-Odon, Amaia. 2012. Presupposition projection and entailment relations: University Pompeu Fabra PhD dissertation.

Gazdar, Gerald. 1979. Pragmatics: Implicature, Pressuposition, and Logical Form. New York, NY: Academic Press.

Geis, Michael L. \& Arnold Zwicky. 1971. On invited inferences. Linguistic inquiry 2(4).

George, Benjamin. 2008. Presupposition Repairs: A Static, Trivalent Approach to Predicting Projection. Los Angeles, CA University of California Los Angeles MA thesis.

Geurts, Bart. 1996. Local satisfaction guaranteed: A presupposition theory and its problems. Linguistics and Philosophy 19(3). 259-294.

Heim, Irene. 1983. On the projection problem for presuppositions. In Daniel P. Flickinger (ed.), West Coast Conference on Formal Linguistics (WCCFL) 2, 114-125. Stanford, CA: CSLI Publications.

Heim, Irene. 1990. Presupposition projection. In Rob van der Sandt (ed.), Reader 
for the Nijmegen Workshop on Presupposition, Lexical Meaning, and Discourse Processes, University of Nijmegen.

Heim, Irene. 1992. Presupposition projection and the semantics of attitude verbs. Journal of Semantics 9(3). 183-221.

Heim, Irene. 2006. On the proviso problem. Handout for talk at the Milan Meeting, Gargano.

Herburger, Elena. 2015. Condional perfection: The truth and the whole truth. In Sarah D'Antonio, Mary Moroney \& Carol Rose Little (eds.), Semantics and Linguistic Theory (SALT) 25, 615-635. Ithaca, NY: CLC Publications.

Karttunen, Lauri. 1973. Presuppositions of compound sentences. Linguistic Inquiry 4(2). 169-193.

Karttunen, Lauri. 1974. Presupposition and linguistic context. Theoretical Linguistics 1(1-3). 181-194.

Karttunen, Lauri \& Stanley Peters. 1979. Conventional implicature. Syntax and Semantics 11. 1-56.

Katzir, Roni. 2007. Structurally-defined alternatives. Linguistics and Philosophy 30(6). 669-690.

Katzir, Roni \& Raj Singh. 2013. A note on presupposition accommodation. Semantics and Pragmatics 6. 1-16.

Lassiter, daniel. 2012. Presuppositions, provisos, and probability. Semantics and Pragmatics 5(2). 1-37.

Mandelkern, Matthew. 2016a. Dissatisfaction theory. In Mary Moroney, Carol Rose Little, Jacob Collard \& Dan Burgdorf (eds.), Semantics and Linguistic Theory (SALT) 26, 391-416. Stanford: CSLI Publications.

Mandelkern, Matthew. 2016b. A note on the architecture of presupposition. Semantics and Pragmatics 9.

Matsumoto, Yo. 1995. The conversational condition on horn scales. Linguistics and Philosophy 18(1). 21-60.

Mayr, Clemens \& Jacopo Romoli. 2016. A puzzle for theories of redundancy: Exhaustification, incrementality, and the notion of local context. Semantics and Pragmatics 9.

Meyer, Marie-Christine \& Uli Sauerland. 2009. A pragmatic constraint on ambiguity detection. Natural Language and Linguistic Theory 27(1). 139-150.

Pérez Carballo, Alejandro. 2009. Toward a dissolution of the proviso problem. In Paul Egré \& Giorgio Magri (eds.), Presuppositions and Implicatures: Proceedings of the MIT-Paris Workshop 60, Cambridge, MA: MITPWL.

Peters, Stanley. 1979. A truth-conditional formulation of Karttunen's account of presupposition. Synthese 40. 301-316.

van Rooij, Robert. 2007. Strengthening conditional presuppositions. Journal of Semantics 24(3). 289-304. 
Satisfied or exhaustified

Rothschild, Daniel. 2011. Explaining presupposition projection with dynamic semantics. Semantics and Pragmatics 4(3). 1-43. doi:10.3765/sp.4.3.

van der Sandt, Rob. 1992. Presupposition projection as anaphora resolution. Journal of Semantics 9(4). 333-377.

Sauerland, Uli. 2004. Scalar implicatures in complex sentences. Linguistics and Philosophy 27(3). 367-391.

Schlenker, Philippe. 2008. Be articulate! A pragmatic theory of presupposition projection. Theoretical Linguistics 34(3). 157-212.

Schlenker, Philippe. 2009. Local contexts. Semantics and Pragmatics 2. 1-78.

Schlenker, Philippe. 2011. The proviso problem: A note. Natural Language Semantics 19. 395-422.

Singh, Raj. 2007. Formal alternatives as a solution to the proviso problem. In T. Friedman \& M. Gibson (eds.), Semantics and Linguistic Theory (SALT) 17, 264-281. Stanford: CSLI Publications.

Singh, Raj. 2008. Modularity and locality in interpretation: Massachusetts Institute of Technology PhD dissertation.

Soames, Scott. 1979. A projection problem for speaker presuppositions. Linguistic Inquiry 10(4). 623-666.

Stalnaker, Robert C. 1973. Presuppositions. Journal of Philosophical Logic (2). 447-457.

Stalnaker, Robert C. 1979. Assertion. Syntax and Semantics 9.

Stalnaker, Robert C. 2014. Context. Oxford: Oxford University Press.

Clemens Mayr

Zentrum für Allgemeine Sprachwissenschaft

Schützenstraße 18

10117 Berlin

mayr@zas.gwz-berlin.de
Jacopo Romoli

Shore Road

Ulster University

Newtownabbey, UK, BT37 0QB

j.romoli@ulster.ac.uk 